Randomized Trial

\title{
Effectiveness of Parasagittal Interlaminar Epidural Local Anesthetic with or without Steroid in Chronic Lumbosacral Pain: A Randomized, Double-Blind Clinical Trial
}

Babita Ghai, MD1, Kushal Kumar, MD¹, Dipika Bansal, MD², Saravdeep S. Dhatt, MS³, Raju Kanukula, MPharma², and Yatindra K. Batra, MD ${ }^{1}$

\footnotetext{
From: ${ }^{1}$ Department of Anaesthesia and Intensive

Care, Post Graduate Institute of Medical Education and Research, Chandigarh, India;

${ }^{2}$ Clinical Research Unit, National Institute of Pharmaceutical

Education and Research, Mohali, Punjab, India; 3Department of Orthopaedics,

Post Graduate Institute of Medical Education and Research, Chandigarh, India

Additional Author Affiliation information on P. 246

Address Correspondence: Dr. Babita Ghai Additional Professor, Department of Anaesthesia and Intensive Care PGIMER, Sector-12

Chandigarh, India-160012 E-mail: ghaibabitaı@gmail.com

Disclaimer: A statement about prior postings and presentations:

The preliminary results of this research work has been presented (poster) at 15th World Congress on Pain held at Buenos Aries, Argentina, October 6-10, 2014. This paper has not been submitted for publication or has not been published anywhere. Conflict of interest: Each author certifies that he or she, or a member of his or her immediate

family, has no commercial association (i.e., consultancies, stock ownership, equity interest, patent/licensing arrangements, etc.) that might pose a conflict of interest in connection with the submitted manuscript.

Manuscript received: 03-24-2015

Revised manuscript received: 03-31-2015 Accepted for publication: 04-01-2015

Free full manuscript: www.painphysicianjournal.com
}

Background: Epidural injections (El) are the most commonly performed minimally invasive intervention to manage chronic low back pain (CLBP) with lumbosacral radicular pain (LRP). Local anesthetic (LA) and/ or steroids are frequently used injectates for $\mathrm{El}$ and are reported with variable effectiveness. The majority of earlier studies have used either caudal, transforaminal (TF), or undefined interlaminar approaches for El. The parasaggital interlaminar (PIL) approach route is reported to have good ventral epidural spread and comparable effectiveness to the TF route. However, there is a lack of head-to-head comparative effectiveness research of LA with or without steroid for managing CLBP with LRP using a PIL approach.

Objective: To compare the effectiveness of El of LA alone and LA with steroid using a PIL approach for managing CLBP with LRP.

Study Design: Randomized, double blind, active control one year follow-up study.

Setting: Interventional pain management clinic in a tertiary care center in India.

Methods: Sixty-nine patients were randomized to receive fluoroscopic guided El of either $8 \mathrm{~mL}$ of $0.5 \%$ lidocaine (group $\mathrm{L}, \mathrm{n}=34$ ) or $6 \mathrm{~mL}$ of $0.5 \%$ lidocaine mixed with $80 \mathrm{mg}(2 \mathrm{~mL})$ of methylprednisolone acetate (group $L S, n=35$ ). Patients were evaluated for pain intensity using $0-10$ numerical rating scale (NRS) and functional disability using Modified Oswestry Disability Questionnaire (MODQ) at baseline; and 2 weeks, one, 2, 3, 6, 9, and 12 months after injection. Patients with inefficacy with the initial injection or response deterioration received an additional injection of the same injectate and dose. Patients were evaluated for achieving effective pain relief (EPR, i.e., $\geq 50 \%$ from baseline), overall NRS and MODQ, number of injections, and presence of ventral and perineural spread over one year follow-up. Primary outcome was proportion of patients achieving EPR at 3 months.

Results: A significantly higher proportion of patients achieved EPR at 3 months in group LS [30 (86\%, $90 \% \mathrm{Cl} 73 \%-93 \%)]$ as compared to group $L[17(50 \%, 90 \% \mathrm{Cl} 36 \%-64 \%)](P=0.02)$. Similar results were obtained at 6,9 , and 12 months, respectively. The probability of achieving EPR was significantly higher in group LS at various time-points during the one year follow-up as compared to group $L(P=0.01) \mathrm{A}$ significant reduction in NRS and improvement in MODQ were observed at all time-points post-intervention compared to baseline $(P<0.001)$ in both groups. NRS and MODQ scores were significantly lower in group $L S$ as compared to group $L$ at all time intervals post baseline. On average patients in group $L$ received $2.0(0.85)$ and group LS received $1.7(0.71)$ injections annually $(P=0.07)$. Ventral epidural spread was comparable in both groups (97\%). No major complications were encountered in either group; however, intravascular spread of contrast was noted during 2 injections (one in each group) requiring relocation.

Limitations: A single center study, lack of documentation of adjuvant therapies like individual analgesic medication, and lack of placebo group.

Conclusions: Using a PIL approach and the addition of steroid to LA for El may provide superior effectiveness in terms of extent and duration of pain relief for managing CLBP with unilateral LRP, even though, local anesthetic alone also was effective.

Trial registration: CTRI/2014/04/004572

Key words: Epidural injection, epidural steroid, chronic low back pain, chronic lumbosacral pain, parasagittal interlaminar

Pain Physician 2015; 18:237-248 
ow back pain (LBP) with or without lumbosacral radicular pain (LRP) is the most common of all spinal and even chronic pain problems (1). It is among the most common chronic disorders with the longest number of years lived with disability in US (2). LRP is most commonly caused by a protrusion of a lumbar intervertebral disc resulting in an inflammatory response around its nerve root $(3,4)$, This inflammatory process is considered to be the cause of LRP (5-7).

Epidural injections (EI) are the most commonly performed minimally invasive intervention in managing chronic low back pain (CLBP) with LRP with a reported increase from 2000 to 2013 of 165\% per 100,000 Medicare beneficiaries $(1,8,9)$. Steroids and local anesthetic (LA) alone or in combination are the most commonly used injectates (10-15). The plausible underlying mechanism of action of epidural steroid administration is to reduce inflammation by inhibiting the synthesis or release of pro-inflammatory mediators and causing a reversible LA effect (16-18). Whereas, LA are shown to cause suppression of nociceptive discharge $(19,20)$, sympathetic reflex arch blockade (20), axonal transport blockade (21), and anti-inflammatory effect (22).

Recently conducted studies using lidocaine with or without steroids have reported variable results with many reporting equal effectiveness (12-14), while some reported the potential superiority of epidural steroids compared with LA alone $(11,15)$ as well as a substantially superior outcome of LA and steroid as compared to LA and saline injected in or away from the epidural space (23) or somewhat better effectiveness of LA as compared to LA and steroid (10).

The majority of earlier studies have used either caudal or undefined interlaminar approaches for EI. It is suggested that El would be more effective if delivered close to the target site, i.e., ventral epidural space (VES). The transforaminal (TF) approach is considered as target specific (delivering injectate in the VES near the nerve root) and is reported to be more effective than the interlaminar route (24-27). However, recent literature (27-31) showed that interlaminar El are as effective as TF or caudal EI $(15,27)$ when performed in contemporary pain management settings using fluoroscopic guidance. These equivalent results may be attributed to a lateral paramedian/parasagittal interlaminar approach toward the side of pain $(28,30,31)$ as compared to the traditional midline approach. We recently reported comparable efficacy of parasagittal interlaminar lumbar (PIL) and TF ESI under fluoroscopic guidance for managing CLBP with unilateral LRP. Equivalent clinical outcomes with both approaches were attributed to similar ventral epidural spread (VES) of injectate (31).

To the best of our knowledge, no head-to-head comparative study has evaluated the effectiveness of El of LA, with or without steroid for CLBP with LRP using a PIL approach. To clarify the controversy of adding steroids to LA for El, we planned to conduct the present study to evaluate the effectiveness of PIL EI of LA alone as compared to LA and steroid in managing patients with CLBP and LRP. We hypothesized that addition of steroid in El of LA using a PIL approach may improve the efficacy.

\section{Methods}

\section{Study Design}

The study was conducted as a single center, randomized, double blind, active control, and parallel group trial. Consolidated Standards of Reporting Trials (CONSORT) guidelines and principles of the Declaration of Helsinki were followed (32). The study was approved by Institute ethics committee (PGIMER, Chandigarh, India) and was registered with Clinical Trial Registry of India (CTRI/2014/04/004572). This was an investigatorinitiated study and intramural institutional resources were primarily utilized.

\section{Participants}

The study was conducted in an interventional pain clinic of a public tertiary care hospital in north India. The clinic received referred patients from various specialist departments (orthopaedic surgeons, neurosurgeons, neurologists, or physiatrists) for interventional pain management. Consecutive patient recruitment was done as per inclusion criteria; adults of either gender aged 18 to 60 years with CLBP and unilateral LRP of $\geq$ 12 weeks duration not responding to medications and physical therapies, having pain score of $\geq 5$ on $0-10$ numerical rating scale (NRS) at the time of enrolment. The diagnostic criteria for LRP were discussed previously $(1,33)$. We obtained written informed consent from all participants. A trained specialist performed a detailed clinical examination to determine the most probable nerve root affected. Magnetic resonance imaging (MRI) was performed in all patients to correlate the symptoms and disc level protrusion. Inclusion criteria focused on unilateral radiculitis and disc herniation.

The patients were excluded if they had severe spinal pathology (large disc herniation occupying more than $60 \%$ of spinal canal, severe central spinal 
stenosis, spondylolisthesis, tumor, or synovial cysts). Patients were also excluded if they had any sensory or motor loss; referred pain because of facet or sacroiliac joint arthropathy, unstable neurological deficits, and cauda equine syndrome; previous lumbar spine surgery; clinically significant or unstable medical or psychiatric illness; or inability to understand the questionnaires. Those having received lumbar El in past, corticosteroids or anesthetics allergy, taking anticoagulants or bleeding diathesis, taking systemic corticosteroids, pregnant and lactating women, or being treated with investigational drug within 30 days of trial were also excluded.

Baseline information including demographics, pain duration, medication, NRS for pain, and modified Oswestry Disability Questionnaire (MODQ) with disability index for functional impairment was recorded at enrollment $(34,35)$.

\section{Randomization and Masking}

Patients were randomized (block of six, software: Random-Randomizer) to receive $\mathrm{El}$ of either $8 \mathrm{~mL}$ of $0.5 \%$ lidocaine (group L) or $6 \mathrm{~mL}$ of $0.5 \%$ lidocaine mixed with $80 \mathrm{mg}(2 \mathrm{~mL})$ of methylprednisolone acetate (DEPO-MEDROL ${ }^{\mathrm{TM}}$ injection, Pfizer products India Pvt. Ltd, Mumbai) (group LS) using a PIL approach. Patients, investigators including outcome assessor, and care providers were unaware of randomization and group allocation. Randomization codes were placed in sealed opaque envelopes and opened at the time of injection by an independent anesthesiologist not involved in the study. As depo preparation of methylprednisolone is a milky white preparation, this independent anesthesiologist prepared the drug according to the randomization code in an opaque syringe under sterile conditions and handed it to the physician performing the procedure. Another step to enhance the blinding and allocation concealment was done by incorporating study cases in between clinical non-study cases during the procedure as well as the follow-up period.

\section{Study Interventions and Procedures}

Before intervention, intravenous access and standard monitoring were established. Baseline heart rate, non-invasive blood pressure, and oxygen saturation were noted. All procedures were performed under Carm fluoroscopic guidance with the patient in a prone position using a PIL approach $(31,36)$. Perineural and VES were noted for each injection. The study drug was administered after fluoroscopic imaging according to the allocation scheme and patients were observed in the recovery room for at least one hour post-procedure.

\section{Assessment and Follow-up}

A blinded investigator followed the patients at 2 weeks, one, 2, 3, 6, 9, and 12 months post-intervention. An average of past 2 weeks observation was recorded for NRS and MODQ score for the initial 2 post-procedure follow-up visits and then past one month observation for subsequent visits. Patients were also assessed for treatment emergent adverse events (TEAE), possible neurologic complications, and any newly developed pain, need for surgical treatment, etc.

\section{Additional Injections}

Additional El were administered of same injectate if there was deterioration in pain relief to $<50 \%$ after initial achievement of pain relief or no pain relief with the initial injection. The subsequent El were administered with a minimum gap of 15 days at least. The patient received no further injection if he developed $T E A E$, experienced $\leq 10 \%$ pain relief, or pain relief lasting for $\leq 7$ days with 2 successive injections. Unblinding was performed for such treatment failure cases and alternative treatments were offered in an open label manner.

\section{Primary and Secondary Outcomes}

The proportion of patients achieving effective pain relief (EPR) at 3 months in each group was considered as the primary endpoint.We defined the approach as "effective" when pain relief was $\geq 50 \%$ reduction from baseline on NRS. The secondary endpoints included overall mean NRS and MODQ index at various time points, ventral and perineural spread, number of injections required, TEAE, and possibly neurological complications.

\section{Co-Interventions and Post-intervention Medications}

All patients received conservative management including analgesics (adjuvant; pregabalin, amitriptyline, opioid, or non-opioid) and/or exercise program during the study. Dose titration of analgesics was done as per patient requirement. Job attendance continued. All patients were encouraged to engage in physical activities. No additional occupation/physical therapy or any other interventions were offered beyond the protocol. 


\section{Statistical Analysis}

The sample size was calculated assuming a clinically significant difference of $25 \%$ in achieving EPR at 3 months. We expected LA alone to achieve a minimum efficacy of $60 \%$ at 3 months $(13,15)$ and further improvement by $25 \%$ was considered clinically meaningful with the addition of steroid (group LS). Having equal allocation, $\alpha$ of $0.5 \%$, power of $90 \%$, the number of patients in each intervention group required was 28 . Adjusting for dropouts and withdrawals, we planned to recruit 34 patients in each group.

The primary and secondary effectiveness analyses were performed on the intention-to-treat (ITT) population, defined as patients who received at least one injection and have one post-procedure assessment. We analyzed all patients according to the group to which they were allocated, regardless of crossovers, surgery, and withdrawal from the study or loss to follow-up. The last observation carried forward (LOCF) was utilized in patients who dropped or were withdrawn from the study.

Demographic data was analyzed using either independent student $t$ test or $\chi 2$ test. The primary endpoint was analyzed using $\chi 2$ test. Repeated parameters (NRS and MODQ) were analyzed using two-way repeated measures analysis of variance (ANOVA). For this analysis, the Mauchly test was used for assumption of sphericity. If found significant, the Greenhouse-Geisser test was used with adjustment for time $\times$ factor, time $\times$ group interaction, and between-subject effects for NRS and MODQ followed by post hoc analysis with Bonferroni correction for multiple comparisons. We used KaplanMeier survival analysis to estimate effective pain relief duration and probability of patient achieving EPR at various follow-up periods. The 2 group differences were analyzed using log-rank test. The Clopper-Pearson Exact method was used to find the $95 \% \mathrm{Cl}$ of EPR proportion and upper limit of $95 \% \mathrm{Cl}$ of complications. $P$ $<0.05$ was considered significant. Statistical software SPSS version 14.0 (SPSS Inc, Chicago, IL) was used for analysis.

\section{Results}

Patients were recruited between May 2013 and February 2014 and were followed for one year. Patient disposition by intervention group is summarized in Fig. 1. Ninety-three out of 310 screened patients were eligible. Eighteen declined to participate, 4 improved before randomization, and 2 did not turn up for the intervention after enrollment but before randomization.
Finally, 69 patients (34 in group L and 35 in group LS) were included and analyzed.

Both groups were similar with respect to preprocedure demographic and clinical characteristics (Table 1). Forty-three (62\%) patients received a second injection and the median interval between the first and second injections was 42 (IQR $15-68)$ days. Eighteen $(26 \%)$ patients received a third injection. The median interval between the second and third injection was 24 (IQR 15 - 61) days. In total, 65 (91\%) patients were successfully followed up.

\section{Primary Outcome}

A significantly higher proportion of patients achieved EPR at 3 months in group LS [30 $(86 \%, 95 \% \mathrm{Cl}$ $71 \%-94 \%)$ ] as compared to group L [ $17(50 \%, 95 \% \mathrm{Cl}$ $34 \%-66 \%)](-0.002)$. Similar results are obtained at 6 , 9 , and 12 months, respectively, as shown in Fig. 2 . At one year of follow-up, a significantly higher relative success of EPR was noted in the LS group $89 \%$ as compared to $59 \%$ in group $L$ and the absolute risk reduction (pain relief) at one year of follow-up was found to be $36 \%$ (95\% Cl $14-53)$ with LS injections and number needed to treat was calculated to be $3(95 \% \mathrm{Cl} 2-7)$. At oneyear follow-up, a significantly higher relative success of EPR was noted in group LS, relative risk $=1.5(95 \% \mathrm{Cl}$ $1.11-2.04), P=0.006$.

\section{Pain-Free Survival Period}

Survival curves showed that the probability of achieving EPR was significantly higher and the painfree survival period was longer in group LS at various times during the 12 months of follow-up as compared to group $L(P=0.01$, Fig. 3 ).

\section{NRS and MODQ Score over Time}

The results of repeated measures ANOVA revealed time $\times$ factor $(P<0.001$ for both NRS and MODQ $)$ and time $\times$ group interaction $(P<0.001$ for NRS and MODQ). Between-group effect was also significant ( $P=0.003$ for NRS and $P=0.002$ for MODQ). Follow-up within group pairwise analysis revealed that NRS and MODQ scores decreased significantly at all time intervals compared with baseline in both groups. Between-group analysis revealed that NRS and MODQ scores were significantly lower in group LS as compared to group $L$ at all time intervals post baseline (Figs. 4 and 5).

\section{Follow-up and Withdrawal}

Seven $(21 \%)$ patients in group L (6 after second EI 


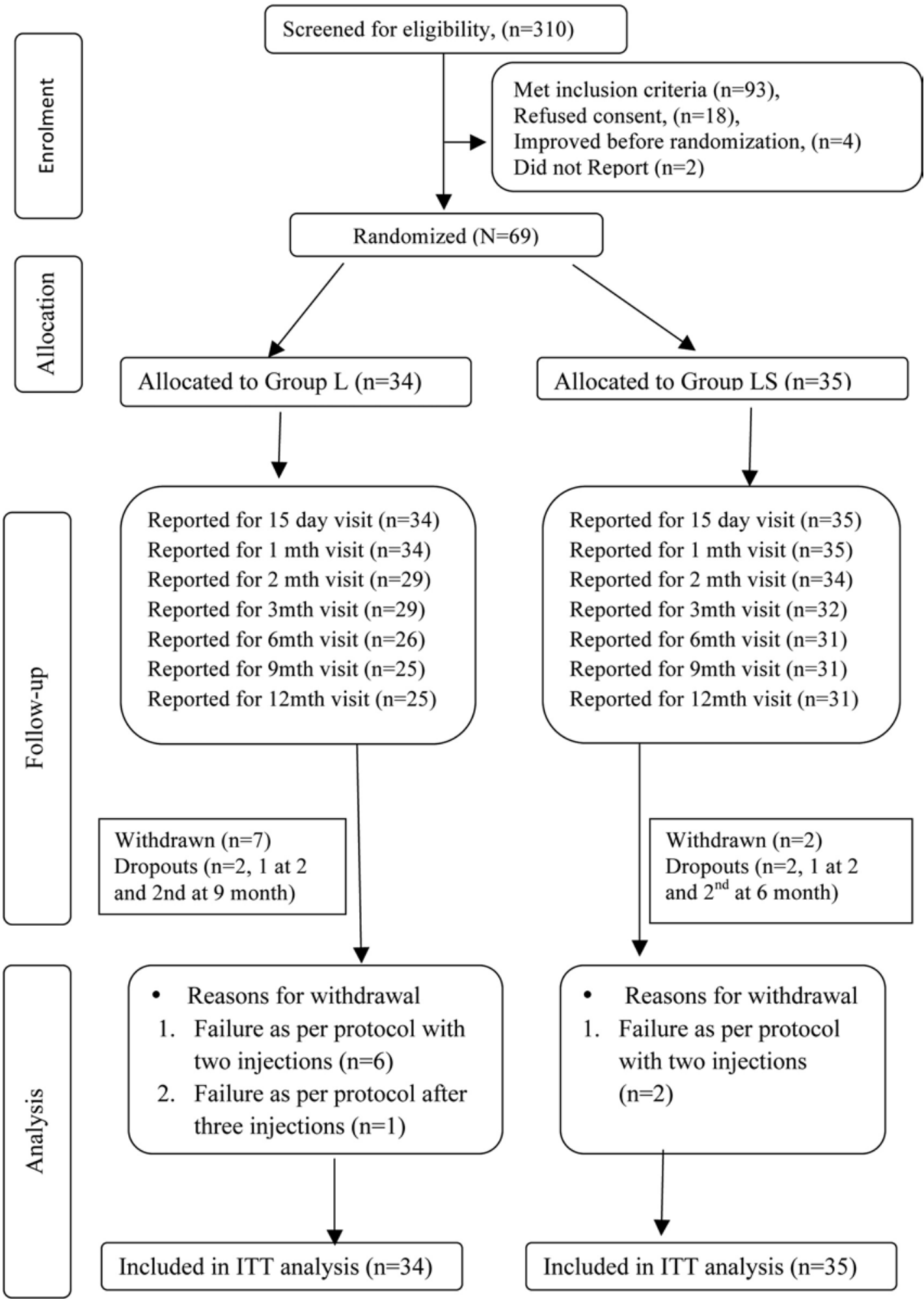

Fig. 1. Flow chart of patients who participated in the study. 
Table 1. Demographic data and baseline characteristics.

\begin{tabular}{|c|c|c|c|c|}
\hline & & Group L $(n=34)$ & Group LS $(n=35)$ & $P$ value \\
\hline Age (Years) & Mean \pm SD & $44.7 \pm 10.5$ & $45.9 \pm 13.3$ & 0.65 \\
\hline \multirow{2}{*}{ Gender, n (\%) } & Male & $15(44)$ & $19(54)$ & \multirow{2}{*}{0.47} \\
\hline & Female & $19(56)$ & $16(46)$ & \\
\hline Weight (Kg) & Mean \pm SD & $66.3 \pm 10.1$ & $68.7 \pm 12.5$ & 0.07 \\
\hline Height $(\mathrm{cm})$ & Mean \pm SD & $163.5 \pm 6.4$ & $165.8 \pm 8.7$ & 0.21 \\
\hline Body mass Index $(\mathrm{Kg} / \mathrm{m} 2)$ & Mean \pm SD & $24.8 \pm 3.6$ & $24.9 \pm 4.1$ & 0.88 \\
\hline Duration of pain (months) & $\begin{array}{c}\text { Mean } \pm \text { SD } \\
\text { Median (IQR) }\end{array}$ & $\begin{array}{c}19.6 \pm 12.5 \\
15(10-25)\end{array}$ & $\begin{array}{c}21.5 \pm 14.8 \\
12(12-36)\end{array}$ & 0.58 \\
\hline Visual Analogue scale $(0-10)$ & $\begin{array}{c}\text { Mean } \pm \text { SD } \\
\text { Median (IQR) }\end{array}$ & $\begin{array}{l}8.0 \pm 1.4 \\
8(8-9)\end{array}$ & $\begin{array}{l}8.0 \pm 1.6 \\
8(8-9)\end{array}$ & 0.92 \\
\hline Modified Oswestry Disability score & $\begin{array}{c}\text { Mean } \pm \text { SD } \\
\text { Median (IQR) }\end{array}$ & $\begin{array}{c}49.6 \pm 12.8 \\
49(42-60)\end{array}$ & $\begin{array}{c}46.8 \pm 14.3 \\
46(37-58)\end{array}$ & 0.94 \\
\hline $\begin{array}{l}\text { Level of Injection, n (\%) } \\
\text { L3-L4 } \\
\text { L4-L5 } \\
\text { L5-S1 }\end{array}$ & $\begin{array}{c}3(4) \\
36(52) \\
30(44)\end{array}$ & $\begin{array}{c}1(3) \\
18(53) \\
15(44)\end{array}$ & $\begin{array}{l}2(6) \\
18(51) \\
15(43)\end{array}$ & 0.85 \\
\hline $\begin{array}{l}\text { Procedure side, n (\%) } \\
\text { Left } \\
\text { Right }\end{array}$ & & $\begin{array}{l}18(53) \\
16(47)\end{array}$ & $\begin{array}{l}17(49) \\
18(51)\end{array}$ & 0.81 \\
\hline
\end{tabular}

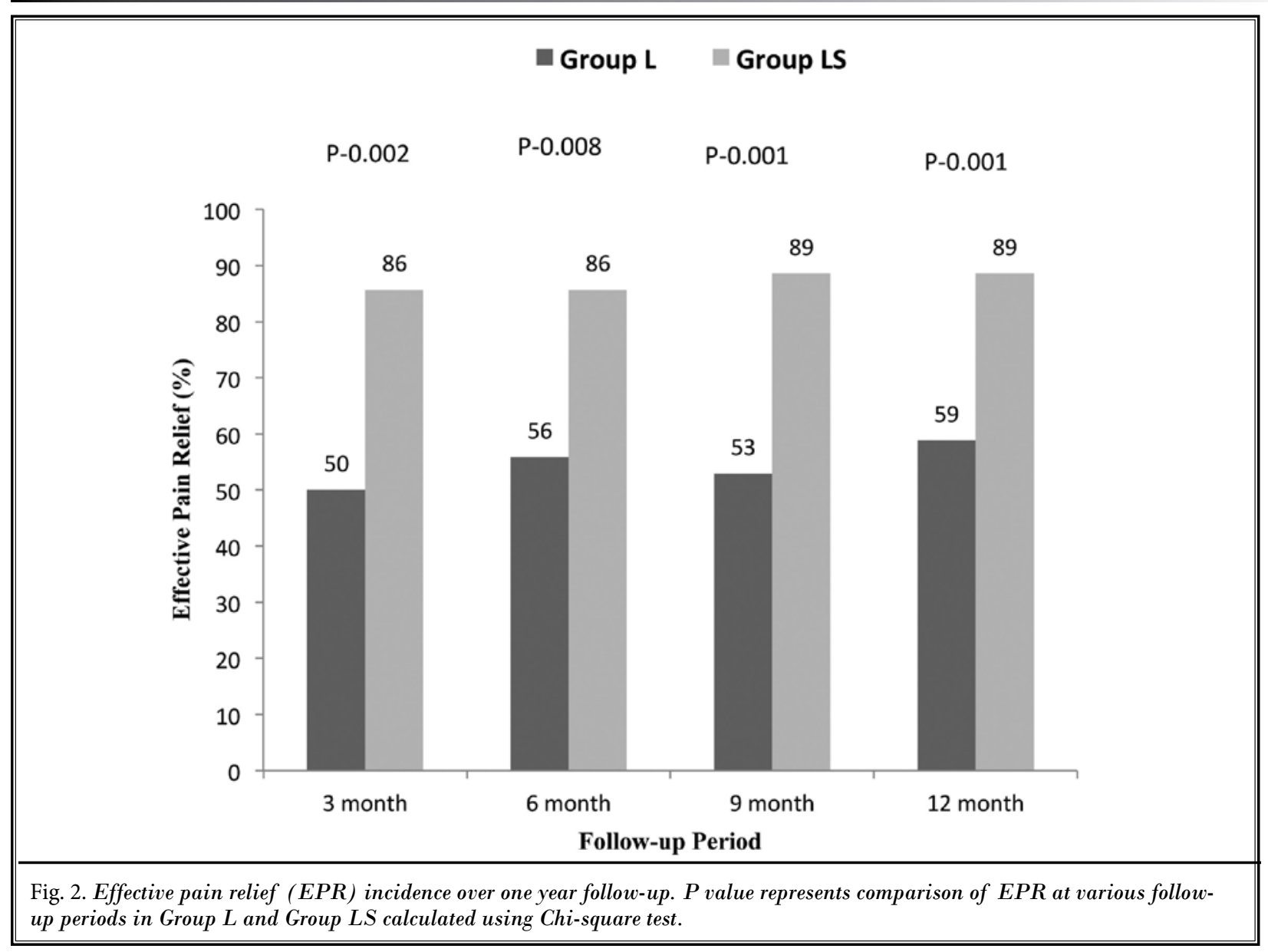


Epidural Local Anesthetic with or without Steroid in Lumbosacral Pain

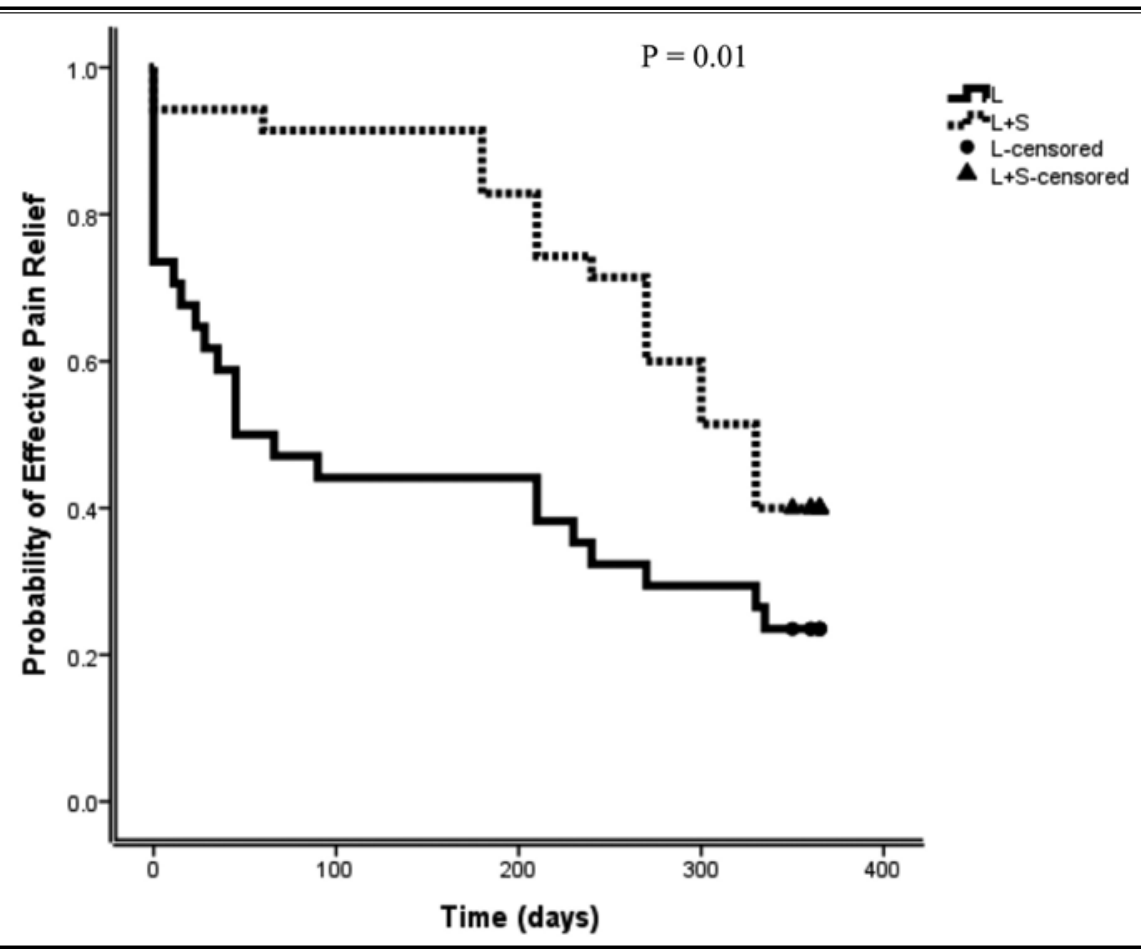

Fig. 3. Kaplan-Meier graph for effective analgesia period. The figure represents probability of achieving effective analgesia at various points of time. The two groups are compared using log rank test.

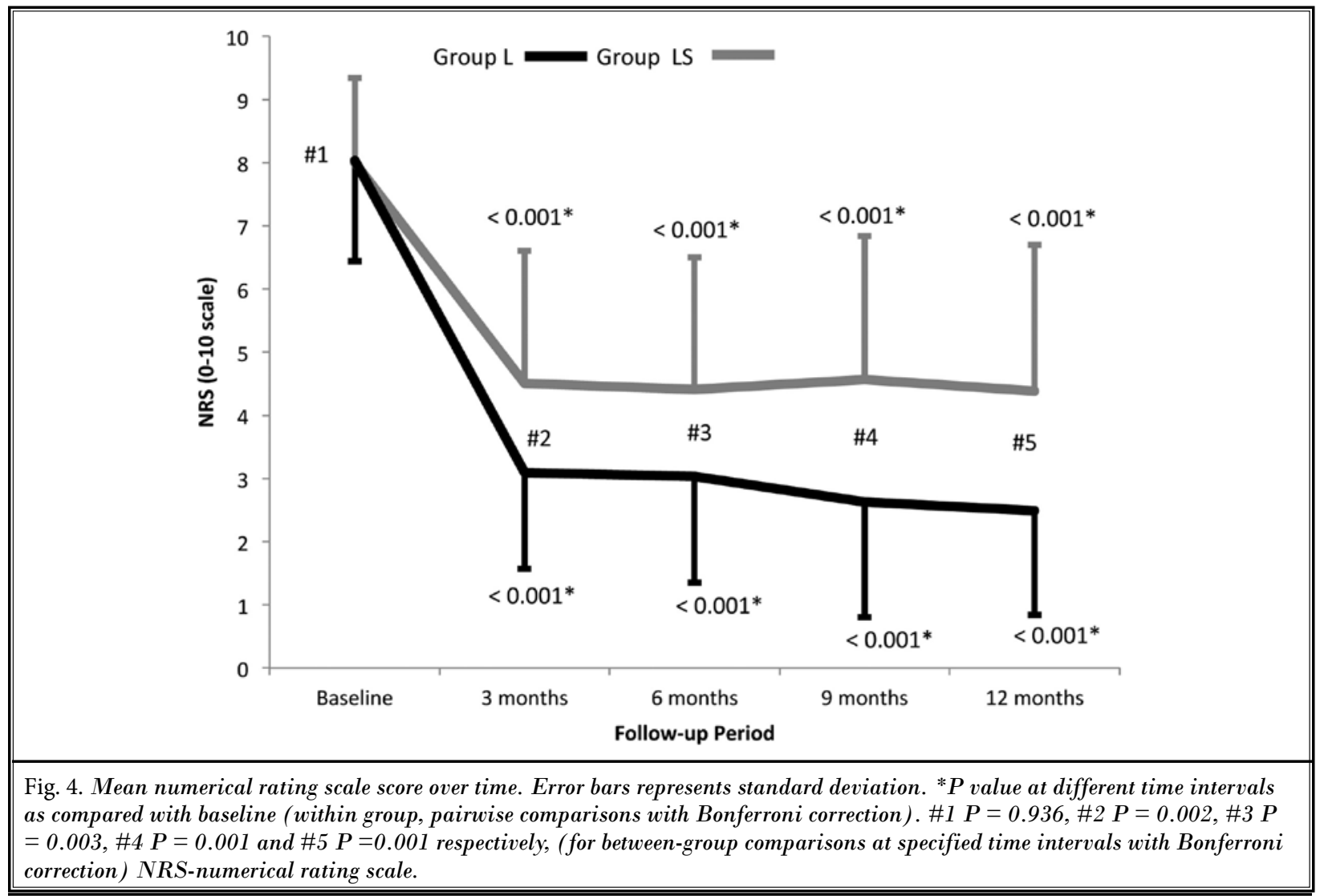




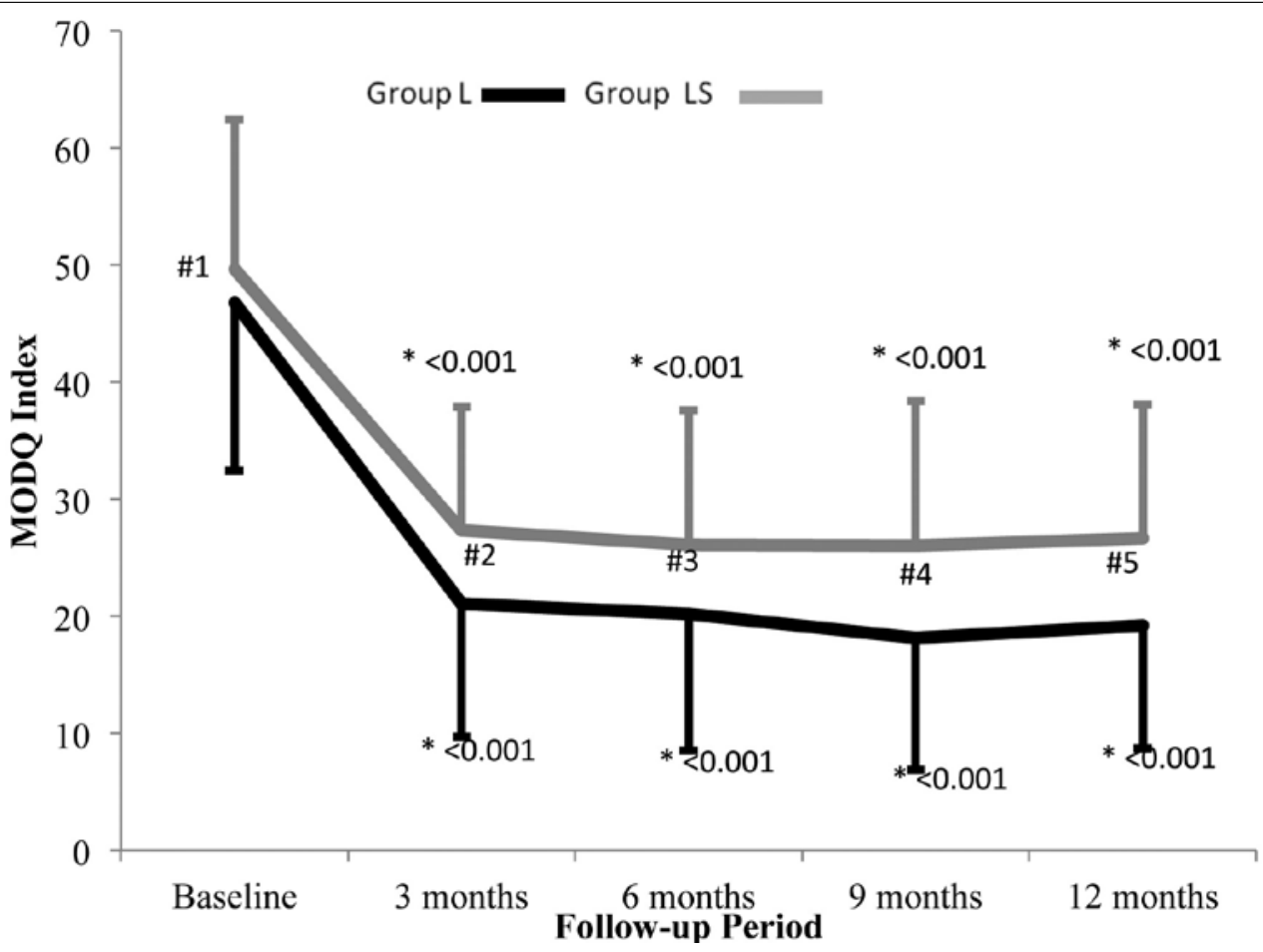

Fig. 5. Mean Modified Oswestry Disability Questionnaire index over time. Error bars represents standard deviation. ${ }^{*} P<0.001$ at different time intervals as compared with baseline (within group, pairwise comparisons with Bonferroni correction). \#1 $P=0.39, \# 2 P=0.02, \# 3 P=0.038$, \#4 $P=0.007$ and \#5 $P=0.007$ respectively, for between-group comparisons at specified time intervals with Bonferroni correction. MODQ-Modified Oswestry Disability Questionnaire.

and one after third EI) and $2(6 \%)$ in group LS (both after second El) were withdrawn from the study due to inefficacy and were offered alternative treatments. None of the patients were withdrawn due to TEAE. Two (6\%) patients in group $L$ (one at 2 months and one at 9 months) and $2(6 \%)$ in group LS (one at 2 months and one at 6 months) were lost to follow-up but were included in analysis (ITT) as per protocol.

\section{Level of Injection}

Levels of injections in both groups were comparable. The majority received epidural steroid injections (ESI) at L4-L5 level (18 in each group). Fifteen in each group received injection at L5-S1 level. One patient in group $L$ and 2 in group LS received injection at L3-L4 level $(P=0.85)$ (Table 1$)$.

\section{Total Number of ESI}

Total ESI administered in the group $L(70)$ and the group LS (60) were comparable $(P=0.07)$. An average (SD) of $2.0(0.85)$ and $1.7(0.71)$ with $95 \% \mathrm{Cl}$ of the difference $(0.03-0.72)(P=0.07$, t test $)$ injections were required in group $L$ and group $L S$, respectively over 52 weeks of follow-up. Twenty-three of 34 (67\%) patients in group $\mathrm{L}$ and 20/35 (57\%) patients in group LS received further injections $(P=0.3)$. Thirteen of 34 $(38 \%)$ in group $L$ and $5 / 35(14 \%)$ in group LS received 3 injections $(P=0.03)$.

\section{Ventral Epidural and Perineural Spread}

VES was comparable, $97 \%$ in each group $(68 / 70$ injections in group $L$ and 58/60 injections in group LS, $P=1.0)$. Perineural spread was also comparable $(97 \%$, $69 / 70$ injections) in group $L$ versus $92 \%$ (55/60 injections) in group LS $(P=0.25)$.

\section{Fluoroscopy Time}

Mean (SD) fluoroscopy time (FT) after all injections was found to be comparable 17.63 (3.7) seconds in group L versus 16.97 (4.3) seconds in LS group, respectively $(P=0.40)$.

\section{Monitoring of the Complications}

No intrathecal, intradiscal, or subdural contrast 
placement was encountered. Intravascular spread of contrast was noted during 2 injections (one in each group) requiring relocation. One patient (group L) developed vasovagal response at the time of drug injection and was managed successfully with an injection of atropine. No patient reported any swelling, redness, or persisting pain at the injection site. No other complication was noted. The exact 95\% Clopper-Pearson $\mathrm{Cl}$ was $0.0 \%-0.10 \%$ in the group $L, 0.0 \%$ to $0.15 \%$ in the group LS, and $0.0 \%-0.08 \%$ for both the groups combined.

\section{Discussion}

The present randomized controlled clinical trial (RCCT) compared epidural lidocaine and epidural lidocaine plus steroid injections using a PIL approach for managing CLBP with unilateral LRP secondary to disC herniation. The results accept the hypothesis that the addition of steroid to lidocaine in El for the treatment of CLBP with LRP improves the extent and duration of EPR substantially. A significantly higher proportion of patients achieved EPR at 3 months as well as at all subsequent follow-ups during the study period in group LS as compared to group L. We also noted that the probability of achieving EPR was significantly higher in group LS as compared to group L. Additionally, a significantly higher number of patients required study withdrawal due to inefficacy in group L; 7 (21\%) patients versus $2(6 \%)$ in group LS requiring alternate treatment. The important finding to note here is that $5 / 7(71 \%)$ of patients who failed initially to achieve EPR with LA improved substantially after LS injections (open label). Although injection requirement was comparable in both groups over one year duration $(P=0.07)$, the proportion of participants requiring a third El was significantly higher in group L, $13(38 \%)$ as compared to group LS $5(14 \%)(P=0.03)$.

Our results are in accordance with the one-year follow-up results of Manchikanti et al (11) where significant superior pain relief at 6 months and better functional improvement at 6 and 12 months were observed with lidocaine plus steroid as compared to lidocaine alone. Moreover, more patients failed in the lidocaine alone group ( $n=6 / 35$ ) as compared to lidocaine with steroid group ( $n=1 / 35$ ). However, the average annual procedures required in our study (2.0 in group $L$ and 1.7 in Group LS) are less than reported by them (4.3 in group $L$ and 4.2 in group LS). This might be because of the difference in study patients' clinical and ethnic characteristics or the use of the PIL approach in our study.
Our results are also in tune with other studies where it is reported that although no significant difference in overall pain relief was found between LA and LS groups $(14,15)$, average pain relief achieved with the first and second procedures was significantly higher in the steroid group $(14,15)$ while the number of injections was considerably higher in the LA group (14).

Also, while comparing LA and LS, Manchikanti et al (13) reported that both the groups demonstrated significant improvement over 2 years. However, overall results showed some superiority in terms of pain relief (at 6 months) and functional ability (at 6 and 12 months) for the steroid addition group. Moreover, the failure rate was also high in the LA alone group as compared to steroid addition group (10 vs 1) (13). The authors extrapolated their results by mentioning that improvement in pain relief could be achieved with the addition of steroid to LA in subsequent injections, if the first injection of LA fails to achieve so in clinical practice. Our results are in line with these previously reported facts and strengthen their assumption, as 5/7 (71\%) participants in our study who failed initially to achieve pain relief with 2 Els of LA improved substantially after LS injections. However, in contrast to these results, Manchikanti et al (10) while comparing LA with LA and steroid using a TF approach reported somewhat better results with LA compared to LA and steroid.

An ample amount of evidence is available in favor of and against El in general (37-44). Despite these debates, the effectiveness of El is described in numerous observational and randomized studies as well as systematic reviews and guidelines $(1,39,40,42,45-47)$. Level I evidence has been generated for the use of $\mathrm{EI}$ with or without steroids and also the superiority of using steroids for managing lumbosacral pain associated with disc herniation and radiculitis (45-47).

In a letter issued (dated 04/23/2014) by the US Food and Drug Administration (FDA), it is warned that corticosteroid injected epidurally in the spine may result in rare, but serious adverse events, including loss of vision, stroke, paralysis, and death (48). Also, the FDA stated that the effectiveness and safety of corticosteroids for epidural use is not well established (48). However, these statements are highly criticized for inadequate literature review and reliance on consensus without critically appraising the available scientific evidence $(49,50)$. The literature reveals that an overwhelming proportion of the serious neurological complications are related to cervical TFEI which constitute only $2.4 \%$ of total EI and $<5 \%$ of all TFEI (51). 
A recent RCT by Friedly et al (52) concluded that the addition of steroid to LA for El offered minimal benefit as compared to El of LA alone for treating spinal stenosis. However, this study is criticized for an inappropriate study design (probable inclusion of acute and subacute pain patients), statistical analysis, and misinterpretation of facts (53). On closer look at the data, it appeared that a significant superior efficacy of steroid-LA group was observed at 3 and 6 weeks in terms of Roland-Morris Disability Questionnaire scores and pain rating scale for leg pain at 3 weeks (53).

Despite the controversies regarding ESI in management of CLBP with LRP, the present study clearly reports that addition of steroid provides significant superior pain relief to epidural LA in terms of extent and duration.

\section{Strengths}

The strengths of this study are consecutive patients' recruitment and strict inclusion criteria. The study design closely approximates the treatment routine being practiced by pain physicians, in which the interventionist tailors the number and spacing of injections as per patients' responses. These design considerations improve the external validity of this study. Other strengths are high internal validity; appropriate masking measures for patients, interventionist, and outcome assessors; adequate follow-up; and adequately powered study.

\section{Limitation}

Being a single center study, the results may not be generalizable to a broader population. Lack of documentation of adjuvant therapies like individual analgesic medication and exercise routines is another limitation. Further, this study may be criticized for not including a placebo group.

\section{Conclusion}

In summary, the results of this RCCT report that Using a PIL approach and the addition of steroid to LA for El may provide superior effectiveness in terms of extent and duration of pain relief for managing CLBP with unilateral LRP, even though, local anesthetic alone also was effective.

These results have significant implications for contemporary interventional pain management settings. This study reports that El under fluoroscopy is an appropriate procedure in properly selected patients and can provide long-term significant pain relief with judicious use. The results are practical and applicable for pain interventionists and may have far reaching effects on health care delivery.

\section{Author Affiliation}

Dr. Ghai is an Additional Professor, Department of Anaesthesia and Intensive Care, Post Graduate Institute of Medical Education and Research, Chandigarh, India. Dr. Kumar is Senior Resident, Department of Anaesthesia and Intensive Care, Post Graduate Institute of Medical Education and Research, Chandigarh, India. Dr. Bansal is Assistant Professor, Clinical Research Unit, National Institute of Pharmaceutical Education and Research, Mohali, Punjab, India. Dr. Dhatt is Assistant Professor, Department of Orthopaedics, Post Graduate Institute of Medical Education and Research, Chandigarh, India. Kanukula is a Pharma Student, Clinical Research Unit, National Institute of Pharmaceutical Education and Research, Mohali, Punjab, India. Dr. Batra is Professor and Head, Department of Anaesthesia and Intensive Care, Post Graduate Institute of Medical Education and Research, Chandigarh, India.

\section{References}

1. Manchikanti L, Abdi S, Atluri S, Benyamin RM, Boswell MV, Buenaventura RM, Bryce DA, Burks PA, Caraway DL, Calodney AK, Cash KA, Christo PJ, Cohen SP, Colson J, Conn A, Cordner H, Coubarous S, Datta S, Deer TR, Diwan S, Falco FJ, Fellows B, Geffert S, Grider JS, Gupta S, Hameed H, Hameed M, Hansen $H$, Helm S, Janata JW, Justiz R, Kaye $A D$, Lee $M$, Manchikanti KN, McManus CD, Onyewu O, Parr AT, Patel VB, Racz GB, Sehgal N, Sharma ML, Simopoulos TT, Singh V, Smith HS, Snook LT,
Swicegood JR, Vallejo R, Ward SP, Wargo BW, Zhu J, Hirsch JA. An update of comprehensive evidence-based guidelines for interventional techniques in chronic spinal pain. Part II: Guidance and recommendations. Pain Physician 2013; 16:S49-S283.

2. US Burden of Disease Collaborators. The state of US health, 1999-2010: Burden of diseases, injuries, and risk factors. JAMA 2013; 310:591-608.

3. Weinstein JN, Tosteson TD, Lurie JD, Tosteson AN, Hanscom B, Skinner JS,
Abdu WA, Hilibrand AS, Boden SD, Deyo RA. Surgical vs nonoperative treatment for lumbar disk herniation: The Spine Patient Outcomes Research Trial (SPORT): A randomized trial. JAMA 2006; 296:2441-2450.

4. Pearson AM, Blood EA, Frymoyer JW, Herkowitz $\mathrm{H}$, Abdu WA, Woodward R, Longley M, Emery SE, Lurie JD, Tosteson TD, Weinstein JN. SPORT lumbar intervertebral disk herniation and back pain: Does treatment, location, or morphology matter? Spine (Phila Pa 1976) 
2008; 33:428-435

5. McCarron RF, Wimpee MW, Hudkins PG, Laros GS. The inflammatory effect of nucleus pulposus. A possible element in the pathogenesis of low-back pain. Spine 1987; 12:760-764.

6. Nygaard OP, Mellgren SI, Osterud B. The inflammatory properties of contained and noncontained lumbar disc herniation. Spine 1997; 22:2484-2488.

7. Arden NK, Price C, Reading I, Stubbing J, Hazelgrove J, Dunne C, Michel M, Rogers P, Cooper C; WEST Study Group. A multicentre randomized controlled trial of epidural corticosteroid injections for sciatica: The WEST study. Rheumatology 2005; 44:1399-1406.

8. Manchikanti L, Pampati V, Falco FJ, Hirsch JA. An updated assessment of utilization of interventional pain management techniques in the medicare population: 2000 - 2013. Pain Physician 2015; 18:E115-E127.

9. Manchikanti L, Helm S, Singh V, Hirsch JA. Accountable interventional pain management: A collaboration among practitioners, patients, payers, and government. Pain Physician 2013; 16:E635-E670.

10. Manchikanti L, Cash KA, Pampati V, Falco FJ. Transforaminal epidural injections in chronic lumbar disc herniation: A randomized, double blind, active-control trial. Pain Physician 2014; 17:E489-501.

11. Manchikanti L, Singh V, Frank JE Falco, Cash KA, Vidyasagar P. Evaluation of the effectiveness of lumbar interlaminar epidural injections in managing chronic pain of lumbar disc herniation or radiculitis: A randomized, double-blind, controlled trial. Pain Physician 2010; 13:343-355.

12. Manchikanti L, Singh V, Cash KA, Pampati $V$, Falco FJ. The role of fluoroscopic interlaminar epidural injections in managing chronic pain of lumbar disc herniation or radiculitis: A randomized, double-blind trial. Pain Pract 2013; 13:547-558.

13. Manchikanti L, Singh V, Cash KA, Pampati $\vee$, Falco FJ. A randomized, double blind, active-control trial of the effectiveness of lumbar interlaminar epidural injections in disc herniation. Pain Physician 2014; 17:E61-E74.

14. Manchikanti L, Singh V, Cash KA, Pampati V, Damron KS, Boswell MV. A randomized, controlled, double-blind trial of fluoroscopic caudal epidural injections in the treatment of lumbar disc herniation and radiculitis. Spine (Phila Pa 1976) 2011; 36:1897-905.

15. Manchikanti L, Vijay S, Kimberly A, Cash RT, Vidyasagar P, Kim S, Damron RN, Boswell MV. Effect of fluoroscopically guided caudal epidural steroid or local anesthetic injections in the treatment of lumbar disc herniation and radiculitis: A randomized, controlled, double blind trial with a two-year follow-up. Pain Physician 2012; 15:273-286.

16. Molloy RE, Benzon HT. Interlaminar epidural steroid injections for lumbosacral radiculopathy. In: Benzon HT, Raja SN, Molloy RE, Liu SS, Fishman SM (eds). Essentials of Pain Medicine and Regional Anesthesia. 2nd edition. Elsevier Churchill Livingstone, Philadelphia, 2005, pp 331-332.

17. Byrod G, Otani K, Brisby H, Rydevik B, Olmarker K. Methylprednisolone reduces the early vascular permeability increase in spinal nerve roots induced by epidural nucleus pulposus application. J Orthop Res 2000; 18:983-987.

18. Lundin A, Magnuson A, Axelsson K, Nilsson O, Samuelsson L. Corticosteroids preoperatively diminishes damage to the C-fibers in microscopic lumbar disc surgery. Spine 2005; 30:2362-2367.

19. Pasqualucci A, Varrassi G, Braschi A, Peduto VA, Brunelli A, Marinangeli $F$, Gori F, Colò F, Paladín A, Mojoli F. Epidural local anesthetic plus corticosteroid for the treatment of cervical brachial radicular pain: Single injection versus continuous infusion. Clin J Pain 2007; 23:551-557.

20. Mao J, Chen LL. Systemic lidocaine for neuropathic pain relief. Pain 2000; 87:7-17.

21. Bisby MA. Inhibition of axonal transport in nerves chronically treated with local anesthetics. Exp Neurol 1975; 47:481-489.

22. Cassuto J, Sinclair R, Bonderovic M. Anti-inflammatory properties of local anesthetics and their present and potential clinical implications. Acta Anaesthesiol Scand 2006; 50:265-282.

23. Ghahreman A, Ferch R, Bogduk N. The efficacy of transforaminal injection of steroids for the treatment of lumbar radicular pain. Pain Med 2010; 11:1149-1168.

24, Schaufele MK, Hatch L, Jones W. Interlaminar versus transforaminal epidural injections for the treatment of symptomatic lumbar intervertebral disc herniations. Pain Physician 2006; 9:361-366.

25. Ackerman WE, Ahmad M. The efficacy of lumbar epidural steroid injections in patients with lumbar disc herniations. Anesth Analg 2007; 104:1217-1222.

26. Parr AT, Diwan S, Abdi S. Lumbar interlaminar epidural injections in managing chronic low back and lower extremity pain: a systematic review. Pain Physician 2009; 12:163-188.

27. Manchikanti L, Singh V, Pampati V, Falco FJ, Hirsch JA. Comparison of the efficacy of caudal, interlaminar, and transforaminal epidural injections in managing lumbar disc herniation: Is one method superior to the other? Korean ] Pain 2015; 28:11-21.

28. Furman MB, Kothari G, Parikh T, Anderson JG, Khawaja A. Efficacy of fluoroscopically guided, contrast-enhanced lumbosacral interlaminar epidural steroid injections: A pilot study. Pain Med 2010; 11:1328-1334.

29. Rados I, Sakic K, Fingler M, Kapural L. Efficacy of interlaminar vs transforaminal epidural steroid injection for the treatment of chronic unilateral radicular pain: Prospective, randomized study. Pain Med 2011; 12:1316-1321.

30. Gharibo CG, Varlotta GP, Rhame EE, Liu EC, Bendo JA, Perloff MD. Interlaminar versus transforaminal epidural steroids for the treatment of subacute lumbar radicular pain: A randomized, blinded, prospective outcome study. Pain Physician 2011; 14:499-511.

31. Ghai B, Bansal D, Kay JP, Vadaje KS, Wig J. Transforaminal versus parasagittal interlaminar epidural steroid injection in low back pain with radicular pain: A randomized, double-blind, active-control trial. Pain Physician 2014; 17:277-290.

32. Schulz KF, Altman DG, Moher D; CONSORT Group. CONSORT 2010 statement: Updated guidelines for reporting parallel group randomized trials. BM] 2010; 340:C332.

33. Govind J. Lumbar radicular pain. Aust Fam Physician 2004; 33:409-412.

34. Vianin M. Psychometric properties and clinical usefulness of the Oswestry Disability Index. J Chiropr Med 2008; 7:161-163.

35. Fairbank JC, Pynsent PB. The Oswestry Disability Index. Spine (Phila Pa 1976) 2000; 25:2940-2952.

36. Ghai B, Vadaje KS, Wig J, Dhillon MS. Lateral parasagittal versus midline interlaminar lumbar epidural steroid injection for management of low back pain with lumbosacral radicular pain: $A$ double-blind, randomized study. Anesth Analg 2013; 117:219-227. 
37. Dworkin RH, O'Connor AB, Kent J, Mackey SC, Raja SN, Stacey BR, Levy RM, Backonja M, Baron R, Harke H, Loeser JD, Treede RD, Turk DC, Wells CD; International Association for the Study of Pain Neuropathic Pain Special Interest Group. Interventional management of neuropathic pain: NeuPSIG recommendations. Pain 2013; 154:2249-2261.

38. Pinto RZ, Maher CG, Ferreira ML, Hancock M, Oliveira VC, McLachlan AJ, Koes $\mathrm{B}$, Ferreira $\mathrm{PH}$. Epidural corticosteroid injections in the management of sciatica: A systematic review and meta-analysis. Ann Intern Med 2012; 157:865-877.

39. Staal JB, de Bie RA, de Vet HC, Hildebrandt J, Nelemans P. Injection therapy for subacute and chronic low back pain: An updated Cochrane review. Spine (Phila Pa 1976) 2009; 34:49-59.

40. Chang Chien GC, Knezevic NN, McCormick Z, Chu SK, Trescot A, Candido KD. Transforaminal versus interlaminar approaches to epidural steroid injections: A systematic review of comparative studies for lumbosacral radicular pain. Pain Physician 2014; 17:E509-E524.

41. Cohen SP, Bicket MC, Jamison D, Wilkinson I, Rathmell JP. Epidural steroids: A comprehensive, evidence based review. Reg Anesth Pain Med 2013; 38:175-200.

42. Bicket MC, Gupta A, Brown CH, Cohen SP. Epidural injections for spinal pain: A systematic review and meta-analysis evaluating the "control" injections in randomized controlled trials. Anesthesiology 2013; 119:907-931.

43. Iversen T, Solberg T, Romner B, Wils- gaard T, Twisk J, Anke A, Nygaard O, Hasvold T, Ingebrigtsen T. Effect of caudal epidural steroid or saline injection in chronic lumbar radiculopathy: Multicentre, blinded, randomised controlled trial. BM] 2011; 343:d5278.

44. Chou R, Huffman L. Guideline for the Evaluation and Management of Low Back Pain: Evidence Review. American Pain Society, Glenview, IL, 2009.

45. Furlan AD, Pennick V, Bombardier C, van Tulder M; Editorial Board, Cochrane Back Review Group. 2009 updated method guidelines for systematic reviews in the Cochrane Back Review Group. Spine (Phila Pa 1976) 2009; 34:1929-1941.

46. Manchikanti L, Hirsch JA, Cohen SP, Heavner JE, Falco FJE, Diwan S, Boswell MV, Candido KD, Onyewu O, Zhu J, Sehgal N, Kaye AD, Benyamin RM, Helm II S, Singh V, Datta S, Abdi S, Christo PJ, Hameed H, Hameed M, Vallejo R, Pampati V, Racz GB, Raj PP. Assessment of methodological quality of randomized trials of interventional techniques: Development of an interventional pain management specific instrument. Pain Physician 2014; 17:E263-E290.

47. Manchikanti L, Falco FJE, Benyamin RM, Kaye AD, Boswell MV, Hirsch JA. A modified approach to grading of evidence. Pain Physician 2014; 17: E319- E325.

48. U.S. Food and Drug Administration. Drug Safety Communications. FDA Drug Safety Communication: FDA requires label changes to warn of rare but serious neurologic problems after epidural corticosteroid injections for pain.
April 23, 2014. www.fda.gov/downloads/ Drugs/Drug- Safety/UCM394286.pdf

49. Manchikanti L, Candido KD, Singh V, Gharibo CG, Boswell MV, Benyamin RM, Falco FJ, Grider JS, Diwan S, Hirsch JA. Epidural steroid warning controversy still dogging FDA. Pain Physician 2014; 17:E451-E474.

50. Manchikanti L, Falco FJ, Benyamin RM, Gharibo CG, Candido KD, Hirsch JA. Epidural steroid injections safety recommendations by the Multi-Society Pain Workgroup (MPW): More regulations without evidence or clarification Pain Physician 2014; 17:E575-E588.

51. Manchikanti L, Hirsch JA. Neurological complications associated with epidural steroid injections. Curr Pain Headache Rep 2015; 19:482.

52. Friedly JL, Comstock BA, Turner JA, Heagerty PJ, Deyo RA, Sullivan SD, Bauer Z, Bresnahan BW, Avins AL, Nedeljkovic SS, Nerenz DR, Standaert C, Kessler L, Akuthota V, Annaswamy T, Chen A, Diehn F, Firtch W, Gerges FJ, Gilligan C, Goldberg H, Kennedy DJ, Mandel S, Tyburski M, Sanders W, Sibell D, Smuck M, Wasan A, Won L, Jarvik JG. A randomized trial of epidural glucocorticoid injections for spinal stenosis. $N$ Engl J Med 2014; 371:11-21.

53. Manchikanti L, Candido KD, Kaye AD, Boswell MV, Benyamin RM, Falco FJ, Gharibo CG, Hirsch JA. Randomized trial of epidural injections for spinal stenosis published in the New England Journal of Medicine: Further confusion without clarification. Pain Physician 2014; 17:E475-E488. 